\title{
Radio-pathological and Clinical Correlation of Aggressive Angiomyxoma: Experience of a Tertiary Care Cancer Hospital
}

\author{
Ekta Dhamija1일 Harshal Aswar ${ }^{2}$ Sawyer Ehmad ${ }^{1}$ \\ Sameer Rastogi2 \\ ${ }^{1}$ Departments of Radiodiagnosis, Dr. B. R. A. Institute Rotary Cancer \\ Hospital, All India Institute of Medical Sciences, New Delhi, India \\ 2 Departments of Medical Oncology, Dr. B. R. A. Institute Rotary Cancer \\ Hospital, All India Institute of Medical Sciences, New Delhi, India \\ ${ }^{3}$ Departments of Pathology, All India Institute of Medical Sciences, \\ New Delhi, India \\ ${ }^{4}$ Departments of Radiation Oncology, Dr. B. R. A. Institute Rotary Cancer \\ Hospital, All India Institute of Medical Sciences, New Delhi, India \\ Indian J Radiol Imaging 2021;31:566-572.
}

\author{
Adarsh Barwad ${ }^{3}$ Rambha Pandey ${ }^{4}$
}

Address for correspondence Dr. Ekta Dhamija, MD, Department of Radiodiagnosis, Room Number 137, First Floor, Dr. B. R. A. Institute Rotary Cancer Hospital, All India Institute of Medical Sciences, New Delhi 110029, India (e-mail: drektadhamija.aiims@gmail.com).

\section{Abstract}

\section{Keywords}

- aggressive angiomyxoma

- laminated appearance

- sarcoma

Background Aggressive angiomyxoma (AAM) is a rare mesenchymal tumor predominantly affecting the pelvis and perineum of females. Due to its variable clinical presentation, it is often misinterpreted and treated as other pathologies like Bartholin gland cyst, vulvar abscess, and hernia. The tumor is locally infiltrative, making its complete surgical removal difficult.

Aim The aim of the study is to highlight and illustrate the imaging and pathological features of AAM.

Materials and Methods After obtaining clearance from the Institutional Ethics Committee, a retrospective study was conducted on patients with histopathological diagnosis of AAM, presenting to the dedicated sarcoma clinic between 2016 and 2019. The demographic, clinical, radiological, pathological, and treatment details were obtained from the institute's database. The magnetic resonance imaging (MRI) and computed tomography images were reviewed to assess different imaging parameters. Follow-up imaging was assessed for residual or recurrent mass in the pelvis or perineum and distant metastasis.

Results A total of four patients were included with an age range of 28 to 50 years. The baseline MRI of these four patients shows pelvic mass extending into the perineum, infiltrating along the surrounding fascial planes with the characteristic laminated appearance on T2-weighted image and gradual intense enhancement following contrast administration. All patients had residual disease post-surgery and were put on hormonal therapy. Conclusion AAMs are locally aggressive, rarely metastasizing mesenchymal tumor that has a specific predilection for the perineum and pelvis of females. MRI features like laminated or striated appearance, post-contrast enhancement, and finger-like infiltrating projections should raise the suspicion of the diagnosis on baseline imaging.
\end{abstract}

DOI https://doi.org/ 10.1055/s-0041-1735913. ISSN $0971-3026$ (c) 2021. Indian Radiological Association. All rights reserved.

This is an open access article published by Thieme under the terms of the Creative Commons Attribution-NonDerivative-NonCommercial-License, permitting copying and reproduction so long as the original work is given appropriate credit. Contents may not be used for commercial purposes, or adapted, remixed, transformed or built upon. (https://creativecommons.org/ licenses/by-nc-nd/4.0/)

Thieme Medical and Scientific Publishers Pvt. Ltd., A-12, 2nd Floor, Sector 2, Noida-201301 UP, India 


\section{Introduction}

The term aggressive angiomyxoma (AAM) was coined by Steeper and Rosai in $1983^{1}$ while describing this rare mesenchymal neoplasm which is locally aggressive and rarely metastasizes. AAM is a rare soft-tissue tumor that is thought to arise from mesenchyme ${ }^{2}$; however, the exact cell of origin is not clear and hence, it has been classified under the category of "tumor of uncertain differentiation" under the 2013 Edition of WHO Classification of Bone and Soft-tissue Tumors. ${ }^{3}$ Only limited literature is available in terms of anecdotal case reports and case series due to the rarity of the tumor. ${ }^{4,5}$ Predominantly affecting females and presenting with nonspecific complaints involving deeper tissues of the pelvis and perineum have been documented. ${ }^{5,6}$

Due to its rarity and variable clinical presentation, it is often misinterpreted as other common pathologies like Bartholin gland cyst, vulvar abscess, hernia, and lipoma which often leads to inadvertent and incomplete surgical excision. ${ }^{7}$ As the name suggests, the tumor is aggressive indicating its infiltrative nature; AAM tends to flow along the fascial and surrounding fat planes, invading or displacing the tissues, viscera, and vessels which render their complete excision difficult and leads to residual and recurrent disease. The incomplete surgery can be attributed to the lack of prior suspicion, absence of preoperative diagnosis, and imaging depicting the extent of the disease. Recurrence rates range from 25 to $47 \%$ with approximately $85 \%$ recurring within 5 years of surgery. ${ }^{4}$

For timely diagnosis, it is important to have a high index of suspicion for AAM as the rate of misdiagnosis at initial presentation has been reported up to $82 \%{ }^{4,8}$ Multiple imaging modalities have been used to evaluate AAM including computed tomography (CT), magnetic resonance imaging (MRI), and ultrasonography. It has variable and nonspecific imaging appearance; however, a "laminated" or "swirling" pattern has been described on the T2-weighted sequence of MRI which is considered to be pathognomonic for AAM. ${ }^{6}$ Thus, MRI is considered as the imaging modality of choice by virtue of its better soft tissue resolution which enables it to provide information about the extent of the mass.

Histopathological examination shows a tumor with low to moderate cellularity with abundant myxoid stroma and numerous thick- and thin-walled vascular channels traversing the stroma. The tumor cells are spindle- and stellateshaped with ill-defined cytoplasm intermingled with collagen fibers. Mitotic activity is usually not seen. The tumor usually invades adjacent soft tissues. Another common finding could be the presence of scattered cells with myxoid features usually zoned around entrapped nerves and vessels. Upon immunohistochemistry, there is usual immunoreactivity for estrogen receptor and progesterone receptor. Focal immunoreactivity for muscle markers can also be seen. ${ }^{9}$ The recent molecular analyses have identified translocation in the $12 q 13-15$ region involving the HMGA2 gene. ${ }^{10}$

In this study, we aim to discuss the imaging features of histopathologically proven AAM in four patients who presented to our tertiary care cancer hospital.

\section{Materials and Methods}

This is a retrospective study that was conducted after obtaining the Institutional Ethics Committee approval; hence, individual patient consent was not obtained separately. Patients presenting to our dedicated sarcoma clinic from 2016 to 2019 with histopathological evidence of AAM were included in the study. The demographic, clinical, radiological, pathological, and treatment details were obtained from the case records available in the institute's database.

Imaging analysis: Baseline imaging was reviewed by our radiologist (E.D.) and the features were recorded on CT and MRI. The CT was studied for the size, extent, and margins of the mass, infiltration of the surrounding structures, vessels, density as compared with muscles, and enhancement pattern. Similarly, MRI was evaluated in terms of signal intensity as compared with muscles on $\mathrm{T} 1$ and $\mathrm{T} 2$-weighted sequences, enhancement pattern on contrast-enhanced sequences, diffusion-weighted images (DWIs, if available) in addition to the site, size, and extent of the mass. The presence of cystic changes and calcification were also looked for. Follow-up imaging was assessed for residual or recurrent mass in the pelvis or perineum and distant metastasis.

Histopathology: Based on the morphology and immunohistochemistry findings, the diagnosis of AAM was offered. In patients who underwent biopsy/surgery or treatment outside before presenting in our institute; the blocks were reviewed by a dedicated sarcoma pathologist (B.A.) and the features were recorded.

Treatment response: Details about surgery or medical treatment were obtained and the response was assessed on follow-up imaging as per mRECIST 1.1 criteria.

Follow up: Till the last visit in the dedicated sarcoma clinic, i.e., April 2020 was considered.

\section{Results}

We had four patients with proven AAMS during the study period of 3 years with a female to male ratio of 3:1 and age ranging from 28 to 50 years. The females presented with complaints of swelling and feeling of a lump in perineum (vagina, labia majora, or perianal location) and the male patient had scrotal swelling. The duration of complaints ranges from 2 to 8 years. The mean age of the patients at presentation was 40.2 years with a mean size of mass $10.7 \mathrm{~cm}$ and a range of 7.7 to $13.6 \mathrm{~cm}$. The clinical and demographic details are highlighted in -Table $\mathbf{1}$.

Imaging: Baseline MRI was available for all patients with $\mathrm{T} 1$ axial, T2 axial, and sagittal images, and postcontrast T1 fat-sat sequences in all. On T1-weighted images, the mass shows a hypointense signal intensity and on T2-weighted images, each patient had a mass with the characteristic "laminated" or "swirled" appearance (-Fig. 1) The mass shows gradual and progressive enhancement on postcontrast sequences with no cystic or calcific changes within. All patients showed laminated appearance on T2-weighted sequence, gradual progressive enhancement after contrast administration, and infiltrative pattern of growth with 
Table 1 Clinical and demographic details of the four patients

\begin{tabular}{|l|l|l|l|l|l|l|}
\hline S. no & $\begin{array}{l}\text { Age/ } \\
\text { Gender }\end{array}$ & $\begin{array}{l}\text { Clinical } \\
\text { presentation }\end{array}$ & $\begin{array}{l}\text { Duration of } \\
\text { symptoms } \\
\text { (years) }\end{array}$ & Treatment received & $\begin{array}{l}\text { Residual/recurrent } \\
\text { disease }\end{array}$ & $\begin{array}{l}\text { Status at last } \\
\text { follow-up }\end{array}$ \\
\hline 1. & $44 / \mathrm{F}$ & Perianal mass & 6 & Surgery f/b GnRH analogue & $\begin{array}{l}\text { Residual mass stable } \\
\text { on medical treatment }\end{array}$ & $\begin{array}{l}\text { On second-line } \\
\text { hormonal therapy } \\
\text { (PR) }\end{array}$ \\
\hline 2. & $28 / \mathrm{F}$ & Vaginal mass & 3 & Surgery f/b GnRH analogue & Residual stable mass & $\begin{array}{l}\text { Mets to lung and } \\
\text { axilla-put on } \\
\text { hormonal therapy } \\
\text { (PR) }\end{array}$ \\
\hline 3. & $50 / \mathrm{M}$ & Scrotal swelling & 2 & Surgery f/b GnRH analogue & Stable residual mass & $\begin{array}{l}\text { On hormonal } \\
\text { therapy (SD) }\end{array}$ \\
\hline 4. & $39 / \mathrm{F}$ & $\begin{array}{l}\text { Mass along labia } \\
\text { majora }\end{array}$ & 8 & Surgery f/b GnRH analogue & Residual stable mass & $\begin{array}{l}\text { On hormonal } \\
\text { therapy (PR) }\end{array}$ \\
\hline
\end{tabular}

Abbreviations: $f / b$, followed by; PR, partial response, PD, progressive disease; SD, stable disease as per mRECIST 1.1 .
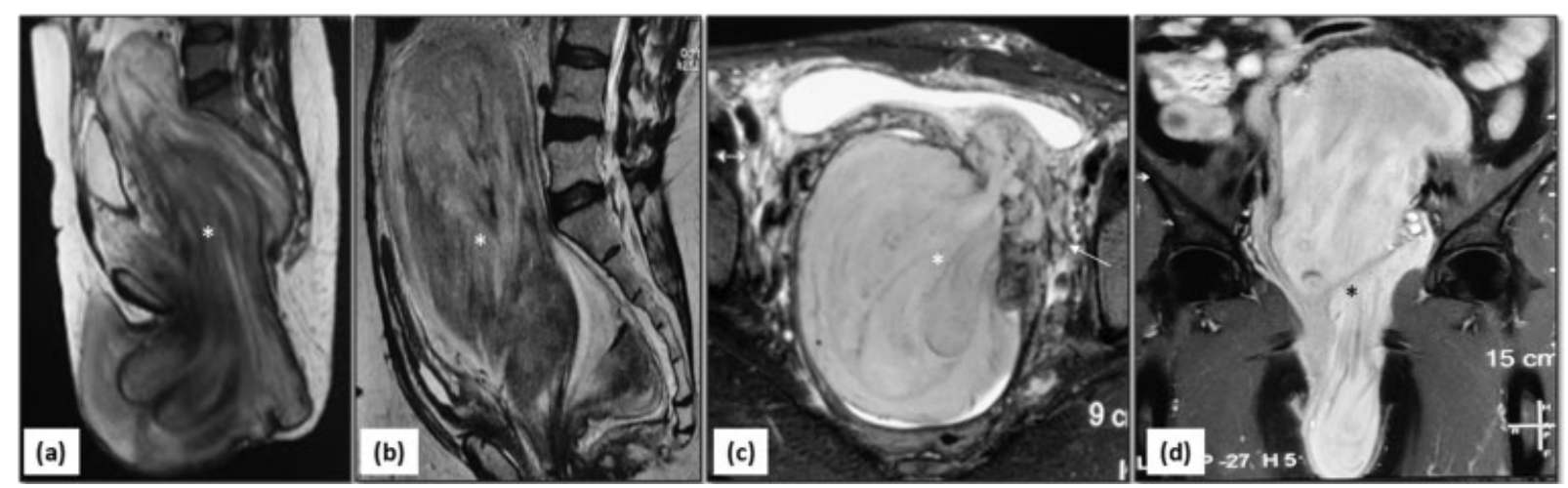

Fig. 1 Laminated appearance on MRI in the four patients of aggressive angiomyxoma: (a, b) T2-weighted sagittal image in patients 1 and 3, respectively, shows the striated layered appearance (asterisk) as alternating high and low signal bands. (c) The axial T2 weighted image of patient 2 also shows the laminated appearance (asterisk) in the mass with finger-like projections along its left lateral border (arrows). (d) Significant enhancement is seen in the postcontrast coronal image of patient 4 with the laminated morphological feature within the mass (asterisk).

finger-like projections along the periphery. DWI images were available for one patient where the mass showed diffusion restriction and a mean ADC value of $1.6 \times 10^{-3} \mathrm{~mm}^{2} / \mathrm{s}$ (-Fig. 2) - Table 2 describes imaging features on MRI in detail.

Follow-up CTs of the chest and abdomen are available for one patient (patient 2) which showed a residual mass in pelvis demonstrating progressive heterogeneous enhancement on single venous phase contrast-enhanced CT. This patient had nodules in the lungs and enlarged necrotic axillary lymph nodes suspicious for metastasis. The primary residual mass showed infiltration of the urinary bladder and finger-like projections along its margins.

Pathology (-Fig. 3): Histological examination in all the tumors shows a low to moderate cellularity with abundant myxoid stroma. The tumor cells were spindle- and stellateshaped with ill-defined cytoplasm. The cells exhibit mild nuclear pleomorphism with round hyperchromatic nuclei with few cells showing small nuclei. Mitotic activity was infrequent. The margins were infiltrative with the encasement of normal nerves and vessels at places. Immunohistochemistry of the estrogen and progesterone receptors was diffusely positive in all the cases. Focal immunoreactivity for smooth muscle actin and desmin was noted in cells showing myxoid differentiation of light microscopy. CD34 was focal in one of the cases. However, S100 was negative. One of the patients showed moderate cellularity with the cells exhibiting oval to spindle morphology and mild nuclear pleomorphism. However, there was no mitotic activity and no significant atypia. The remaining cases were mildly cellular with traversing blood vessels and abundant myxoid stroma with monomorphic spindle to stellate-shaped cells.

Treatment and follow-up: Patients underwent incomplete surgery followed by adjuvant hormonal therapy ( $\mathrm{GnRH}$ analogues). Only one patient progressed on first-line hormonal therapy and later responded to second-line hormonal therapy; the remaining two patients showed partial response and one patient had stable disease on first-line hormonal therapy only (-Fig. 4). One patient developed lesions in the lungs and axilla (within 6 months of diagnosis of AAM) which were evaluated for metastases. The axillary lymph node biopsy did not yield any viable tissue and the patient refused for a repeat biopsy; hence, she was put on Goserelin (GnRH analogue). Since the axillary lymph nodes 


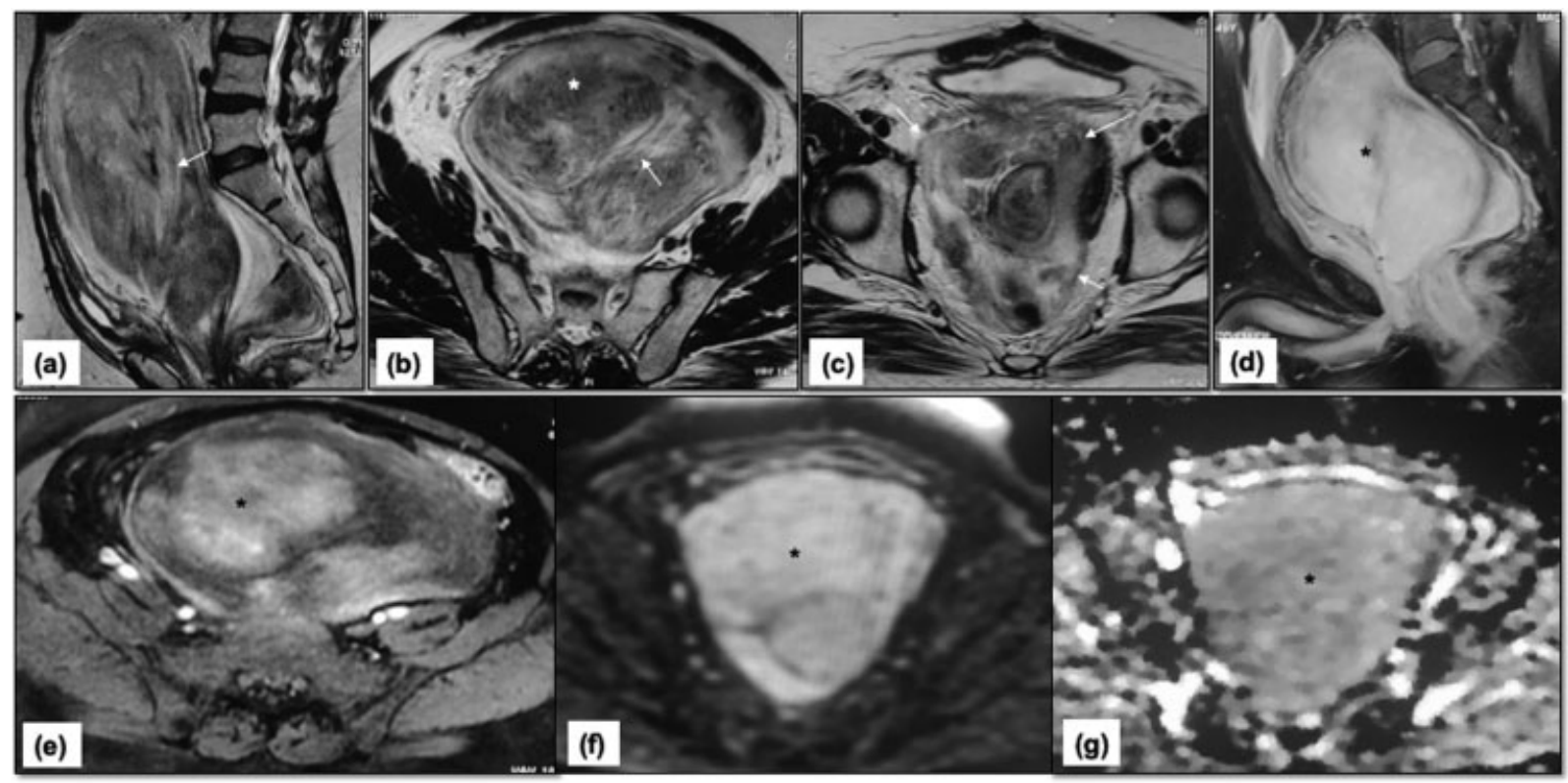

Fig. 2 MRI features of AAM: the pelvic mass shows a predominant hypointense signal on T2-weighted image (a) with an internal laminated or striated appearance (arrows in $\mathbf{a}$ and $\mathbf{b}$ ) seen as alternate high and low signal bands. Its infiltrative nature is seen as finger-like projections along the ill-defined borders extending into the surrounding planes (arrows in $\mathbf{c}$ ). (d, e) The mass shows gradual intensity enhancement after the administration of contrast (asterisk) and restriction on DWI and ADC images ( $\mathbf{f}, \mathbf{g})$. AAM, aggressive angiomyxoma; ADC, apparent diffusion coefficient; DWI, diffusion-weighted image.

Table 2 Imaging features of aggressive angiomyxomas on MRI

\begin{tabular}{|c|c|c|c|c|c|c|c|c|c|}
\hline Patient & $\begin{array}{l}\text { Size at } \\
\text { baseline }\end{array}$ & Extent & T1 & $\mathrm{T} 2$ & $\begin{array}{l}\text { Enhancement } \\
\text { on CEMR }\end{array}$ & $\begin{array}{l}\text { Cystic } \\
\text { changes }\end{array}$ & Calc & $\begin{array}{l}\text { Finger-like } \\
\text { projections }\end{array}$ & $\begin{array}{l}\text { Laminated } \\
\text { appearance }\end{array}$ \\
\hline 1 & $45 \times 25 \mathrm{~cm}$ & $\begin{array}{l}\text { Rectovesical } \\
\text { location with } \\
\text { extension to } \\
\text { perineum }\end{array}$ & Нypo & Hyper & + & - & - & + & + \\
\hline 2 & $8.6 \times 7.2 \mathrm{~cm}$ & $\begin{array}{l}\text { Retrovesical } \\
\text { location with } \\
\text { extension to } \\
\text { lateral pelvic } \\
\text { walls and vagina }\end{array}$ & Нуро & Hyper & + & - & - & + & + \\
\hline 3 & $\begin{array}{l}12.8 \times \\
10.4 \times 9.6 \mathrm{~cm}\end{array}$ & $\begin{array}{l}\text { Scrotal lesion } \\
\text { with extension } \\
\text { to inguinal canal }\end{array}$ & Нyро & Hyper & + & - & - & + & + \\
\hline 4 & $\begin{array}{l}35 \times 25 \times \\
10 \mathrm{~cm}\end{array}$ & $\begin{array}{l}\text { Rectouterine } \\
\text { lesion with } \\
\text { presacral } \\
\text { extension }\end{array}$ & Нуро & Hyper & + & - & - & + & + \\
\hline
\end{tabular}

decreased by $40 \%$ and lung lesions were stable, the lesions were considered metastatic, and the response was categorized as a partial response.

All patients are alive till the last clinic visit with a duration of follow-up ranging from 13 to 90 months.

\section{Discussion}

Angiomyxoma is usually a benign tumor that displaces neighboring organs rather than invading them. It is more common in women of reproductive age and mostly develops in the pelvis, vulva, or perineum in the fourth to fifth decade. ${ }^{1}$ In men, it may develop in the perineum or inguinoscrotal region. ${ }^{5}$ The incidence in females is significantly higher than in males (female-to-male ratio of $6: 1)^{6}$ which was observed in our study as well (a female to male ratio of 3:1).

Most of the AAM patients present with a slow-growing mass in the pelvic and perianal regions that is either asymptomatic or associated with regional pain, dyspareunia, or a pressure-like sensation. Clinical diagnosis before surgery is difficult since the differential diagnosis on clinical 


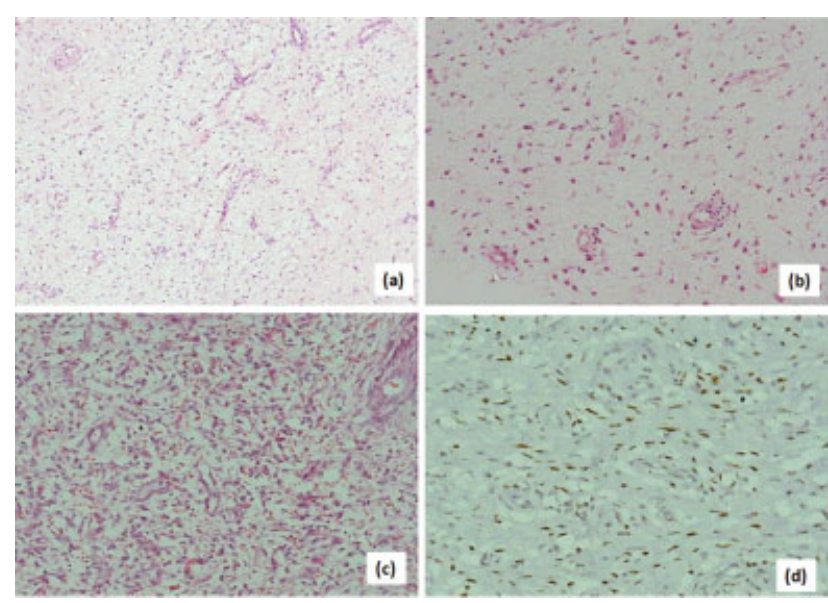

Fig. 3 Histopathological findings in aggressive angiomyxoma: (a) Low power picture from a case of aggressive angiomyxoma showing relatively low cellularity with abundant myxoid matrix and many traversing thin-walled blood vessels. (H\&E 100x). (b) On high power, the pauci-cellular tumor shows monomorphic spindle-to stellateshaped cells embedded in myxoid stroma. The nuclei are small with scanty cytoplasm and indistinct cytoplasmic boundaries (H\&E 200x). (c) Another case of aggressive angiomyxoma showing moderate cellularity with cells exhibiting mild nuclear pleomorphism and ovalto spindle-shaped nuclei and scanty to moderate amount of cytoplasm (H\&E 200x) and (d) Immunostain for estrogen receptor showing nuclear immunoreactivity in spindle cells.

examination includes lesions like vulval abscess, Bartholin gland cyst, cyst of mesonephric duct, vaginal hernia, or levatorani muscle hernia. This often leads to misdiagnosis and incomplete surgical excision. The female patients in our study presented with initial symptoms of nontender mass in perianal, vaginal, and labia majora and the male patient had swelling in the inguinoscrotal region. All these patients underwent excision of the mass before presenting to our institute with residual/recurrent mass. It emphasizes the role of preoperative imaging in determining the exact size and extent of the tumor.

A review of the radiology literature revealed limited information on the imaging features of AAMs. In a series of 10 patients, Outwater et $\mathrm{al}^{11}$ found the typical laminated tumor morphology on T2-weighted imaging and contrastenhanced MRI. In other case reports, the typical MRI findings of laminated T2 signal intensity characteristics have been described. ${ }^{12,13}$ Our study elaborates on previously published literature by describing the CT and MRI characteristics of these tumors and specifically assessing T2-weighted imaging and contrast-enhanced CT in the detection of internal laminated appearance. The ultrasonography (US) and CT features of AAM have been described. ${ }^{14}$ Upon US, the mass may appear hypo-echoic or cystic. The CT features are variable and include hypoattenuating or isoattenuating mass involving the pelvis and perineum with enhancement in the contrast-enhanced scan, which may show the classical swirled appearance. In the series of six cases reported by Outwater et al, ${ }^{11}$ only $50 \%$ of the cases showed the classical swirling architecture on CT.

The imaging differential diagnosis includes myxoma, infiltrating angiolipoma, and infiltrating liposarcoma. Myxoma

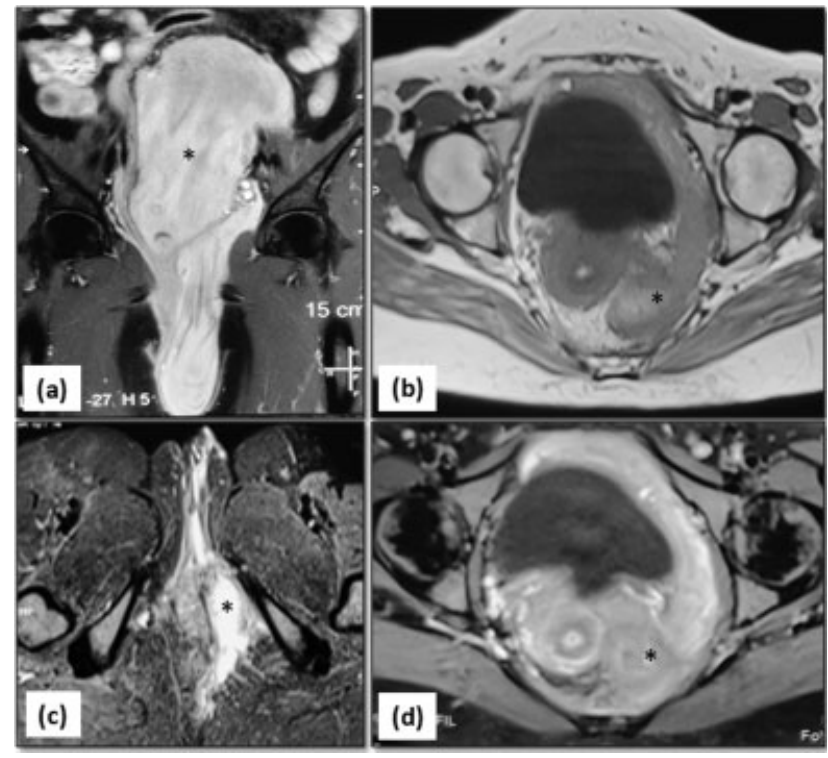

Fig. 4 Follow-up and response assessment: (a) Baseline MRI shows large enhancing mass in the pelvis extending into the perineum into left labia majora (asterisk). (b, c) Postoperative MRI shows residual mass (asterisk) along the left side of the pelvis extending along the labia majora (c) which remains stable on hormonal therapy as seen on MRI after 6 months of initiating the medical treatment (d).

is a benign mesenchymal neoplasm that most frequently occurs in older patients. However, myxomas are mainly intramuscular and show no significant vascularity. ${ }^{15}$ Infiltrating angiolipoma is usually found in the thigh region and as the name implies it infiltrates and replaces the involved muscle and subcutaneous tissue. ${ }^{16}$ The lack of high fat content is a key feature in differentiating the angiomyxoma from myxoid liposarcoma and infiltrating angiolipoma. ${ }^{17}$

Due to the rarity of this disease, treatment recommendations are based on case reports and small series. A wide surgical resection is the treatment of choice, sometimes after preoperative angiographic embolization to decrease the size of the tumor. ${ }^{18}$ But, because of its frequently large size and finger-like extensions along the organs (urogenital tract and rectum), wide excision is not always possible and/or may cause significant morbidity in young patients. In this series, upon initial imaging evaluation, the tumors appeared bulky with a mean long-axis dimension of $10.7 \mathrm{~cm}$ (range, 7$14 \mathrm{~cm}$ ) with $50 \%$ of cases showing a maximal diameter of more than $10 \mathrm{~cm}$. Furthermore, the prognostic value of extensive surgical resection to obtain clear margins is questioned. A review of over 100 cases by Chan et al $^{19}$ showed that patients with clear resection margins have similar chances of remaining disease free ( $50 \%$ at 10 years) compared with those having tumor-involved resection margins (40\%). Later publications confirmed these findings. ${ }^{5,18}$ These observations explain that incomplete resection is acceptable nowadays if followed by long-term follow-up and careful monitoring for timely identification and prompt resection of relapse.

Treatment involving chemotherapy and radiotherapy has been disappointing, probably due to the low mitotic activity of the tumors. ${ }^{18-20}$ AA is likely hormone dependent as 
suggested by the reproductive age of the patients, the few cases reported during pregnancy, and the frequent expression of hormone receptors. ${ }^{5}$ Thus, gonadotropin-releasing hormone agonists have been administered to AA patients in the postoperative and in the preoperative setting with dramatic responses, facilitating surgery, or avoiding mutilating surgery. ${ }^{21-23}$

After treatment, long-term follow-up is required as late recurrences have been described up to 14 years following treatment ${ }^{19}$ and around $71 \%$ of recurrences occur in the first 3 years regardless of the initial tumor size and age of the patient. ${ }^{19}$ In our series, all the patients had residual disease on follow-up. Distant metastasis from AAM is extremely rare, and currently, there are three cases reported around the world. ${ }^{24-26}$ The first case is a 63year-old woman with lung and lymph node metastasis. The second case is a 27-year-old woman with multiple postoperative recurrences, who was diagnosed with lung metastasis after a few years and died from her disease. The third case is a recurrent AAM; the tumors invaded into the inferior vena cava and right atrium and also into both the lungs. These three cases had lung metastases. ${ }^{26}$ In our experience, we had one patient who had suspicious metastases to lung and axillary lymph nodes. The patient had a partial response to hormonal therapy till the last follow-up. Because of this unpredictable biological behavior of AAM, some groups recommended classifying AAM as moderate malignant tumors.

Periodic clinical examination may be insufficient and imaging studies, such as MRI, are fundamental. ${ }^{2}$ They may detect recurrence early, when the tumor is smaller in size, making surgery easier to perform or allowing the use of less morbid percutaneous ablative therapeutic strategies such as radiofrequency ablation or cryotherapy. ${ }^{2}$

Our study is limited by its retrospective study design and the small number of patients from a single cancer center, owing to the rarity of the neoplasm.

\section{Conclusion}

AAMs are locally aggressive, mesenchymal tumors that have specific predilections for the perineum and pelvis of females in the fourth decade of life. The angiomyxomas typically show local recurrence and are extremely rare to metastasize. The MR appearances of AAMs are characteristic, with the "laminated" appearance on the T2 weighted sequence, being diagnostic for pelvic AAMs. While surgery remains the mainstay of treatment, adjuvant treatment in the form of hormonal/chemotherapy is routinely prescribed due to the higher chances of local recurrences and long-term follow-up is also required.

Institute's Ethics Approval Number IEC 527/05.06.2020.

Funding

None.

\section{Conflict of Interest}

None declared.

\section{References}

1 Steeper TA, Rosai J. Aggressive angiomyxoma of the female pelvis and perineum. Report of nine cases of a distinctive type of gynecologic soft-tissue neoplasm. Am J Surg Pathol 1983;7(05): 463-475

2 Brunelle S, Bertucci F, Chetaille B, Lelong B, Piana G, Sarran A. Aggressive angiomyxoma with diffusion-weighted magnetic resonance imaging and dynamic contrast enhancement: a case report and review of the literature. Case Rep Oncol 2013;6(02): 373-381

3 Fletcher CDM, Bridge JA, Hogendoorn P, Mertens F. WHO Classification of Tumours of Soft Tissue and Bone. 4th ed. WHO; 2013; IARC WHO Classification of Tumours, No 5 . ISBN-13 9789283224341

4 Brzezinska BN, Clements AE, Rath KS, Reid GC. A persistent mass: a case of aggressive Angiomyxoma of the vulva. Gynecol Oncol Rep 2018;24:15-17

5 Fetsch JF, Laskin WB, Lefkowitz M, Kindblom LG, Meis-Kindblom JM. Aggressive angiomyxoma: a clinicopathologic study of 29 female patients. Cancer 1996;78(01):79-90

6 Chen H, Zhao H, Xie Y, Jin M. Clinicopathological features and differential diagnosis of aggressive angiomyxoma of the female pelvis: 5 case reports and literature review. Medicine (Baltimore) 2017;96(20):e6820

7 Sutton BJ, Laudadio J. Aggressive angiomyxoma. Arch Pathol Lab Med 2012;136(02):217-221

8 Bai HM, Yang JX, Huang HF, et al. Individualized managing strategies of aggressive angiomyxoma of female genital tract and pelvis. Eur J Surg Oncol 2013;39(10):1101-1108

9 Fletcher CDM, Unni KK, Mertens F, eds. World Health Organization Classification of Tumours. Pathology and Genetics of Tumours of Soft Tissue and Bone Lyon: IARC Press; 2002:189-190

10 Rawlinson NJ, West WW, Nelson M, Bridge JA. Aggressive angiomyxoma with $\mathrm{t}(12 ; 21)$ and HMGA2 rearrangement: report of a case and review of the literature. Cancer Genet Cytogenet 2008; 181(02):119-124

11 Outwater EK, Marchetto BE, Wagner BJ, Siegelman ES. Aggressive angiomyxoma: findings on CT and MR imaging. AJR Am J Roentgenol 1999;172(02):435-438

12 Li X, Ye Z. Aggressive angiomyxoma of the pelvis and perineum: a case report and review of the literature. Abdom Imaging 2011;36 (06):739-741

13 Foust-Wright C, Allen A, Shobeiri SA. Periurethral aggressive angiomyxoma: a case report. Int Urogynecol J Pelvic Floor Dysfunct 2013;24(05):877-880

14 Surabhi VR, Garg N, Frumovitz M, Bhosale P, Prasad SR, Meis JM. Aggressive angiomyxomas: a comprehensive imaging review with clinical and histopathologic correlation. AJR Am J Roentgenol 2014;202(06):1171-1178

15 Elchalal U, Lifschitz-Mercer B, Dgani R, Zalel Y. Aggressive angiomyxoma of the vulva. Gynecol Oncol 1992;47(02):260-262

16 Chew FS, Hudson TM, Hawkins IF Jr. Radiology of infiltrating angiolipoma. AJR Am J Roentgenol 1980;135(04):781-787

17 Stewart ST, McCarthy SM. Case 77: aggressive angiomyxoma. Radiology 2004;233(03):697-700

18 Han-Geurts IJ, van Geel AN, van Doorn L, Eggermont AM, Verhoef CM den Bakker. Aggressive angiomyxoma: multimodality treatments can avoid mutilating surgery. Eur J Surg Oncol 2006;32 (10):1217-1221

19 Chan YM, Hon E, Ngai SW, Ng TY, Wong LC. Aggressive angiomyxoma in females: is radical resection the only option? Acta Obstet Gynecol Scand 2000;79(03):216-220 
20 Suleiman M, Duc C, Ritz S, Bieri S. Pelvic excision of large aggressive angiomyxoma in a woman: irradiation for recurrent disease. Int J Gynecol Cancer 2006;16(Suppl 1):356-360

21 Giles DL, Liu PT, Lidner TK, Magtibay PM. Treatment of aggressive angiomyxoma with aromatase inhibitor prior to surgical resection. Int J Gynecol Cancer 2008;18(02):375-379

22 Poirier M, Fraser R, Meterissian S. Case 1. Aggressive angiomyxoma of the pelvis: response to luteinizing hormone-releasing hormone agonist. J Clin Oncol 2003;21(18):3535-3536

23 Shinohara N, Nonomura K, Ishikawa S, Seki H, Koyanagi T. Medical management of recurrent aggressive angiomyxoma with gonad- otropin-releasing hormone agonist. Int J Urol 2004;11(06): 432-435

24 Siassi RM, Papadopoulos T, Matzel KE. Metastasizing aggressive angiomyxoma. N Engl J Med 1999;341(23):1772

25 Blandamura S, Cruz J, Faure Vergara L, Machado Puerto I, Ninfo V. Aggressive angiomyxoma: a second case of metastasis with patient's death. Hum Pathol 2003;34(10):1072-1074

26 Geng J, Cao B, Wang L. Aggressive angiomyxoma: an unusual presentation. Korean J Radiol 2012;13(01):90-93 